УДК 551.578.46: 550.42

\title{
ГЕОХИМИЧЕСКАЯ ХАРАКТЕРИСТИКА СНЕЖНОГО ПОКРОВА Г. ТОБОЛЬСК
}

\author{
Московченко Дмитрий Валерьевич1, \\ moskovchenko1965@gmail.com \\ Пожитков Роман Юрьевич', \\ pozhitkov-roma@yandex.ru
}

Соромотин Андрей Владимирович², asoromotin@mail.ru

1 Тюменский научный центр СО РАН, структурное подразделение Институт проблем освоения Севера, Россия, 625026, г. Тюмень, ул. Малыгина, 86.

2 Тюменский государственный университет, Россия, 625003, г. Тюмень, ул. Володарского, 6.

Актуальность исследования обусловлена усилением техногенного загрязнения урбанизированных территорий с развитой промышленностью.

Цель: оценка уровня аэротехногенного загрязнения в г. Тобольск по данным изучения микроэлементного состава твердой фазы снежного покрова.

Объекты: фоновые ландшафрты и техногенные урбоэкосиситемы, включающие различные ффункциональные зоны города.

Методы: эколого-геохимическое опробование снежного покрова, определение физико-химических характеристик снега (рH, электропроводность, минерализация), количества пылеаэрозолей в снеготалых водах, анализ элементного состава тверофазной составляющей с использованием методов спектрометрии с индуктивно связанной плазмой и атомно-эмиссионной спектрометрии. Вычисление показателей, характеризующих экологическую ситуацию (коэффрициентов концентрации Кс, суммарного загрязнения Zc, суммарной имиссии элементов Zd).

Результаты. В Тобольске выявлено типичное для урбоэкосистем подщелачивание снеготалых вод, рост их минерализации и электропроводности. Пылевая нагрузка в городе возрастает относительно фона в 4,7 раза, среднее значение составляет 15,2 мг/м² в сутки. Интенсивность выпадения пылеаэрозолей ниже, чем в крупных городах с развитой промышленностью. Главной причиной запыления снежного покрова, роста минерализации, электропроводности и рН снеготальх вод является движение транспорта. На прилегающей к городу фроновой территории твердофразные выпадения обогащены халькофильными элементами, которые в составе субмикронных частиц переносятся из отдаленных промышленных регионов. В городе ассоциация элементов-загрязнителей, включающая $\mathrm{Ti}, \mathrm{Mn}, \mathrm{Co}, \mathrm{Ni}, \mathrm{W}$, свидетельствует о влиянии эрозионно-почвенной составляющей (Ti, Mn), автотранспорта за счет сжигания моторных топлив (Ni), истирания металлических частей (W, Co). Городская промзона, включающая Тобольский нефтехимический комбинат и ТЭЦ, не является существенным источником поступления пылеаэрозолей, поскольку не превосходит другие функциональные зоны города по интенсивности пылевых выпадений и содержанию элементов-загрязнителей. Подсчет показателей суммарного загрязнения Zc и имиссии элементов Zd показал, что Тобольск характеризуется низким уровнем загрязнения, за исключением участков с интенсивным движением автотранспорта.

Ключевые слова:

Снежный покров, пылевой аэрозоль, Тобольск, тяжелые металлы, суммарное загрязнение.

\section{Введение}

По данным Федеральной службы государственной статистики, в настоящее время в городах проживает 75 \% населения России [1]. Поэтому оценка экологического состояния урбанизированных территорий является важнейшим условием для формирования комфортной и безопасной среды проживания людей. Однако научные исследования в этом направлении проводятся преимущественно в крупных городах, а многие малые и средние остаются зачастую слабо исследованными. Так, в Тюменской области изучение экологического состояния городской среды проводилось главным образом в Тюмени, в то время как второй по численности населения город - Тобольск, почти не был изучен. Вместе с тем по материалам, представленным в [2], по количеству выбросов в атмосферу от стационарных источников Тобольск мало уступает Тюмени.
Для изучения атмосферных выпадений очень часто используют снежный покров [3-5]. Доказано [6], что отбор проб снежного покрова является эффективным методом мониторинга загрязнения атмосферного воздуха в северных регионах. В Сибири продолжительность залегания снега составляет 5-9 месяцев, что позволяет объективно проанализировать особенности поступления загрязнителей. В 2020 г. нами было проведено изучение геохимических свойств снежного покрова Тобольска и прилегающей условнофоновой территории. Поскольку формирование техногенных потоков и ореолов рассеяния во многом связано с характером распределения твердых взвешенных частиц [7], основное внимание было уделено твердофазной составляющей.

Тобольск расположен в юго-западной части Западно-Сибирской равнины, в подзоне южной тайги [8]. Климат континентальный, с продолжительной 
холодной зимой. Устойчивый снежный покров залегает в среднем 5,5 месяцев, с 30 октября по 14 апреля [9]. Преобладают ветра южного и западного направлений. Из годового количества осадков на холодный период приходится около 20 \%, это определяет относительную сухость зимнего сезона.

Численность населения Тобольска на 2020 г. составляет 102,0 тыс. человек [10]. Крупнейшим промышленным предприятием является ООО «СИБУР Тобольск» (ранее Тобольский нефтехимический комбинат). Основными направлением деятельности предприятия является переработка легких углеводородов, поставляемых по продуктопроводу газоперерабатывающими заводами севера Тюменской области. В Тобольске также функционируют предприятия энергетики (Тобольская ТЭЦ), машиностроения (ЗАО «Судоверфь»), развито производство стройматериалов (ООО «Железобетон», ООО ЗЖБИ № 4). Крупнейшая промышленная зона города, образованная нефтехимическим комбинатом и ТЭЦ, расположена на расстоянии 8 км в восточном направлении от зоны жилой застройки. Тобольск - важнейший транспорт- ный узел, через который идут потоки автомобильного и железнодорожного транспорта в северные нефтегазодобывающие районы. Протяженность маршрутной сети города по состоянию на 2020 г. составляет 421 км. Среди функциональных зон города преобладают участки, относящиеся к зонам транспортной инфраструктуры, производственной и коммунальноскладской [10].

Целью работы была оценка уровня аэротехногенного загрязнения в г. Тобольск по данным изучения микроэлементного состава твердой фазы снежного покрова. В исследовании были поставлены следующие задачи: определить интенсивность выпадения пылеаэрозолей, установить ассоциацию химических элементов-загрязнителей в твердофазных выпадениях, оценить количество поступления поллютантов, дать оценку экологической ситуации.

Актуальность данной тематики подтверждается большим числом работ зарубежных исследователей, в которых элементный состав снежного покрова является основным объектом исследования при оценке аэротехногенного загрязнения [11-13].

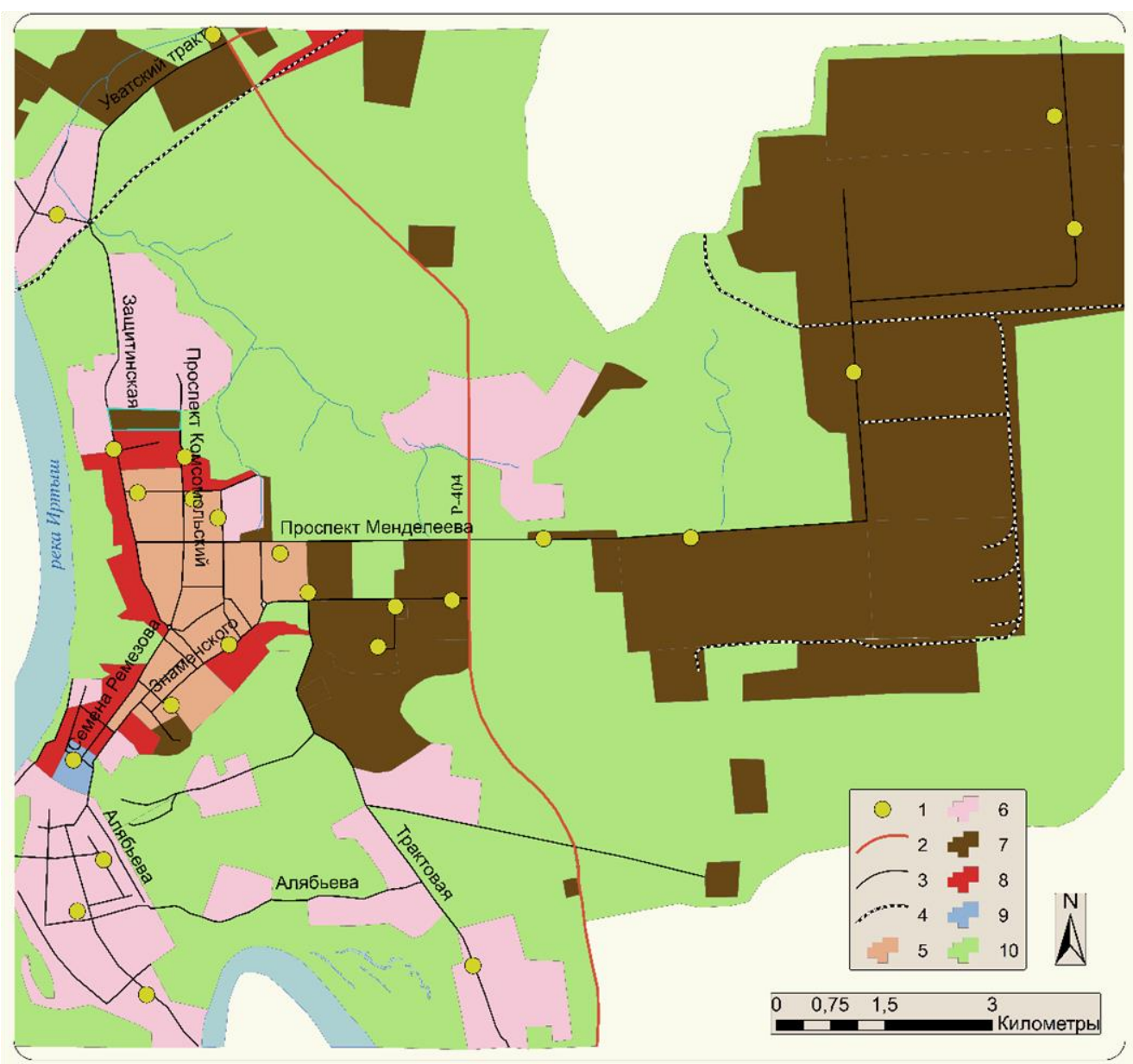

Pис. 1. Схема опробования: 1 - пункты опробования; 2 - федеральная автотрасса Р-404; 3 - железная дорога Тюмень-Сургут; 4 - дороги общегородского пользования; 5 - зона многоэтажной застройки; 6 - зона малоэтажной застройки; 7 - зоны производственного и коммунально-складского назначения; 8 - общественноделовая зона; 9 - зона историко-культурного иентра города; 10 - рекреационная зона

Fig. 1. Study area: 1 - sampling points; 2 - Federal highway R-404; 3 - Tyumen-Surgut railway; 4 - city roads; 5 - zone of high-rise buildings; 6 - zone of low-rise buildings; 7 - zones for industrial and communal storage purposes; 8 - public and business area; 9 - historical and cultural center of the city; 10 -recreational zone 


\section{Материалы и методы}

Опробование снежного покрова было проведено 9-10 марта 2020 г. По данным метеонаблюдений, формирование устойчивого снежного покрова в зимний период 2019-2020 гг. началось 8 ноября, количество осадков, выпавшее до начала опробования, составило 101 мм [14], что близко к среднемноголетним величинам [9]. В зимний период 2019-2020 гг. наблюдалось отчетливое доминирование ветров южного, юго-западного и юго-восточного румбов.

Исследования проводились по общепринятой методике $[15,16]$. Смешанные пробы отбирали весовым снегомером на территории города и на фоновых участках, удаленных от города на расстояние от 9 до 20 км в северном, южном и юго-восточном направлениях. Условно-фоновые пробы были отобраны в разных ландшафтных условиях - на безлесных участках, в таежном лесу и на сельхозугодьях. Схема опробования в городе приведена на рис. 1.

При отборе проб определяли глубину снежного покрова, плотность снега и влагозапас. Пробы помещали в пластиковые контейнеры с крышкой и доставляли в химико-экологическую лабораторию Института экологии и рационального природопользования ТюмГУ. В общей сложности на территории города были отобраны 24 пробы, на фоновых участках 7 проб. Таяние снега происходило при комнатной температуре. В талых пробах измеряли величину $\mathrm{pH}$ с использованием ионометров HI83141 и HydroMaster НM-500. Минерализацию и электропроводность определяли с помощью кондуктометра СОМ-100. 3атем пробы были профильтрованы через беззольные нитроцеллюлозные фильтры (Millipore) c размером пор 0,45 мкм. Массу пыли на фильтре после высушивания определяли путем взвешивания на лабораторных аналитических весах с дискретностью 0,1 мг.

Элементный состав твердофазных выпадений определен в аналитическом центре ИПТМ РАН (г. Черноголовка). Содержание макро- и микроэлементов, включая тяжелые металлы (ТМ) и металлоиды определяли с использованием методов атомно-эмиссионной спектрометрии (ICP-AES) и масс-спектрометрии с индуктивно связанной плазмой (ICP-MS).

Статистическая обработка результатов была проведена в программе Excel. Поскольку распределение значений минерализации, электропроводности и содержания большинства химических элементов не соответствовало нормальному закону, в качестве средних величин было подсчитано среднее геометрическое значение. Для оценки геохимических свойств пылевых выпадений были подсчитаны кларки концентрации $(K K)$ и рассеяния $(K P)$. При подсчетах были применены значения кларков элементов в верхней части континентальной земной коры, использованные при анализе геохимических свойств снежного покрова восточной Москвы [17] и объединяющие величины, полученные различными исследователями в последние десятилетия. Для тех элементов, значения кларков которых в указанной работе отсутствовали, были использованы кларки по Григорьеву [18]. Для определения техногенной составляющей в формировании состава пылеаэрозолей проведено вычисление коэффициента обогащения $K O$ :

$$
K O=\frac{\left(C_{i} / C_{\mathrm{A}}\right) \text { проба }}{\left(C_{i} / C_{\mathrm{Al}}\right) \text { земная кора }},
$$

где $C_{i}$ и $C_{\mathrm{Al}}$ - содержание интересующего элемента и алюминия в пробе или в земной коре.

Пылевую нагрузку Pn определяли по формуле:

$$
P n=\frac{m}{S T},
$$

где $m$ - масса пыли на фильтре; $S$ - суммарная площадь отбора проб; $T$ - временной интервал в сутках между моментом опробования и датой установления устойчивого снежного покрова. Зимой 2019/20 г. продолжительность залегания снега до опробования составила 123 суток.

Экологическая оценка проводилась путем вычисления следующих показателей:

- коэффициентов концентрации элементов

$$
K c=\frac{C}{C_{\phi}},
$$

где $C$ - концентрация элемента во взвеси в городе; $C_{\phi}$ - концентрация на условно-фоновой территории;

- коэффициентов превышения выпадений над фоном

$$
K d=\frac{D}{D_{\phi}},
$$

где $D$ - масса элемента, поступающего на поверхность снежного покрова в городе; $D_{\phi}-$ на условно фоновой территории;

- суммарного показателя загрязнения

$$
Z c=\sum K c-(n-1) ;
$$

- показателя суммарной имиссии элементов

$$
Z d=\sum K d-(n-1),
$$

где $n$ - число химических элементов с $K c$ или $K d>1,5$.

Поскольку значения показателей $K c$ и $K d$ могут изменяться в зависимости от выбора исследуемых элементов и их количества, для сопоставления мы использовали те же элементы, которые применялись для экологической оценки выпадения пылеаэрозолей в Москве [17]. К ним относятся $\mathrm{Cd}, \mathrm{Pb}, \mathrm{Ni}, \mathrm{Co}, \mathrm{Cr}, \mathrm{Be}$ (1-й класс опасности), $\mathrm{Ag}, \mathrm{As}, \mathrm{Bi}, \mathrm{Cu}, \mathrm{Mn}, \mathrm{Sb}, \mathrm{Sn}, \mathrm{Sr}$, $\mathrm{Zn}$ (2-й класс опасности), Mo, V (3-й) и $\mathrm{W}, \mathrm{Fe}, \mathrm{Ti}$ (4-й). Уровень загрязнения и экологической опасности загрязнения снежного покрова металлами и пылью оценивался в соответствии со шкалой распределения значений $Z c$ и $Z d$, приведенной в [19]. Для выделения геохимических ассоциаций химических элементовзагрязнителей был проведен кластерный анализ.

\section{Результаты и обсуждение}

Средняя высота снежного покрова составила в городе 50 см, на фоновых участках -49 см. Плотность снега была одинакова $-0,22$ г $/ \mathrm{cm}^{3}$. Таким образом, показатели снегонакопления были сходными как на 
урбанизированной территории, так и в загородной зоне. Снеготалые воды на фоновых участках имели слабокислую реакцию. Среднее значение $\mathrm{pH}(5,1$ ед.) было несколько ниже, чем рН снеготалых вод на территории ХМАО-Югры (5,3 ед.) [20]. В городе при преобладании слабокислой реакции снеготалых вод встречаются пробы с нейтральной реакцией. Среднее значение рН 6,0 ед., увеличение по сравнению с фоном составило 0,9 ед. Ранее подщелачивание снеготалых вод было отмечено вблизи населенных пунктов и автодорог на территории ХМАО-Югры [20] и в Тюмени [21]. Причиной роста $\mathrm{pH}$ считается выпадение карбонатных пылевых частиц [2]. Уровень подщелачивания в Тобольске можно оценить как умеренный. Так, в восточном административном округе Москвы подщелачивание снежного покрова относительно фоновых территорий составило в среднем 0,4 [17]. В Нижневартовске был выявлен боле существенный рост $\mathrm{pH}$ - от 5,5 ед. на фоновом участке до 7,1 ед. на территории города [22].

На фоновой территории минерализация снеготалых вод в среднем составляет 11 мг/л. Полученная величина, судя по литературным источникам [21, 23], типична для фоновых условий в Западной Сибири. Считается, что минерализацию атмосферных осадков $M \leq 15$ мг/л можно принять за региональный фон [24]. В городе среднее значение минерализации составило 25 мг/л, максимальное значение достигает 563 мг/л и вызвано использованием противогололедных реагентов на дорогах. По сравнению с фоном минерализация в среднем увеличилась в 2,3 раза, рост минерализации можно оценить как умеренный. Для сравнения, в Восточном административном округе Москвы минерализация снеготалой воды в 4 раза выше фонового значения и увеличивается вдоль автомагистралей и в жилой зоне высокой этажности в 6-9 раз [17].

Электропроводность снеготалых вод в городе по сравнению с фоном увеличивается в среднем в 2 раза от 17 до 32 мкСм/см. Экологической нормой предложено считать значение проводимости осадков 60 мкСм/см [24]. В Тобольске в четырех пробах (17\%) это значение превышено.

Количество пылевых выпадений в снежном покрове является важным индикатором экологического состояния атмосферного воздуха [25-27]. Известно, что в снеге полярных районов, не подверженных влиянию местных источников воздействия, содержание пылевых частиц составляет 0,2-3 мг/л [28]. В районе Тобольска содержание пыли в снеге на фоновых участках было выше и в среднем составило 5,7 мг/л, что свидетельствует о наличии полей рассеяния от разнообразных источников, как местных, так и связанных с межрегиональным переносом. Наличие на юге Тюменской области западного переноса поллютантов от крупных промышленных предприятий Урала, расположенных на расстоянии 250-350 км, отмечалось в [29].

Фоновые показатели пылевой нагрузки в районе Тобольска варьировали от 1,4 до 11,6 мг/м² в сутки

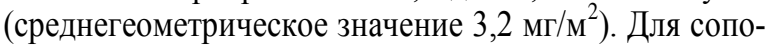
ставления, в Томской области фоновая величина су- точных пылевых выпадений составляет 7 мг/м² в сутки [30]. На территории Омской и Новосибирской областей количество пылевых выпадений ниже - около $3 \mathrm{мг} / \mathrm{M}^{2}$ в сутки [31, 32]. Таким образом, в районе Тобольска фоновая величина пылевой нагрузки находится на уровне средних значения для юга Западной Сибири.

В городе содержание пылевых частиц увеличива-

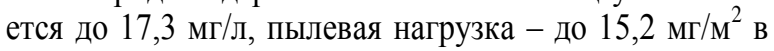
сутки (среднее геометрическое значение). Полученные величины свидетельствуют об умеренной интенсивности пылевых выпадений. В условиях интенсивного техногенеза, связанного с выбросом большого количества пылеаэрозолей (например, в районах металлургических производств), значения $P n$ на 1-2 порядка выше. Так, в Норильском промышленном районе пылевая нагрузка местами превышает $1000 \mathrm{мг} / \mathrm{m}^{2}$ в сутки [33]. В городах, где уровень воздействия промышленности не так высок, пылевая нагрузка близка к полученным на территории Тобольске значениям. Так, средняя величина суточных выпадений твердых частиц из атмосферы за зимний период в восточном административном округе Москвы 27 мг/м² [17]. В Томске среднесуточное значение пылевой нагрузки в 2011 и 2013 гг. составило соответственно 25 и $28 \mathrm{мг} / \mathrm{m}^{2}$ [27]. В Тобольске по сравнению с фоном величина пылевой нагрузки возрастает в 4,7 раза, что сходно с показателями, выявленными в промышленных центрах Сибири. Так, в Томск-Северской промышленной агломерации в 2006-2013 гг. пылевая нагрузка в 3,6-5,4 раза превышала фоновый уровень [34].

Величина пылевой нагрузки на территории города значительно варьирует в зависимости от форм и интенсивности воздействия. Наблюдается разброс значений на два математических порядка - от фоновых величин до показателей, соответствующих высокому, опасному уровню загрязнения в соответствии со шкалой нормирования, приведенной в $[17,19]$. Максимальное значение в Тобольске (406 мг/м² в сутки) было выявлено вблизи транспортной развязки на пересечении федеральной автотрассы, соединяющей юг Тюменской области с северными округами, и проспекта, связывающего промышленную зону Тобольска с кварталами жилой застройки. Существенное варьирования пылевой нагрузки типично для урбанизированных территорий. Так, в Томске количество пылевых выпадений меняется от 16 до 303 мг/м² в сутки [35].

Распределение физико-химических показателей по функциональным зонам города, представленное на рис. 2, показывает, что главной причиной запыления снежного покрова, роста минерализации, электропроводности и рН снеготалых вод является движение транспорта. Именно вблизи автотрасс отмечены максимальные значения этих показателей. На участках многоэтажной застройки также наблюдается рост минерализации и электропроводности снеготалых вод, однако он выражен значительно слабее. Промышленная зона отличается низкими показателями пылевой нагрузки и содержания водорастворимых солей. Чаще 
всего отмечается существенное негативное воздействие крупных промышленных объектов на химический состав снеготалых вод [36]. Но в более ранних экологических исследованиях промзоны Тобольска были выявлены только единичные случаи превыше- ния содержания взвешенных частиц в снеготалых водах по сравнению с фоновым уровнем и не отмечено прямой связи между размещением загрязненных участков и преобладающими направлениями распространения выбросов от техногенных источников [37].
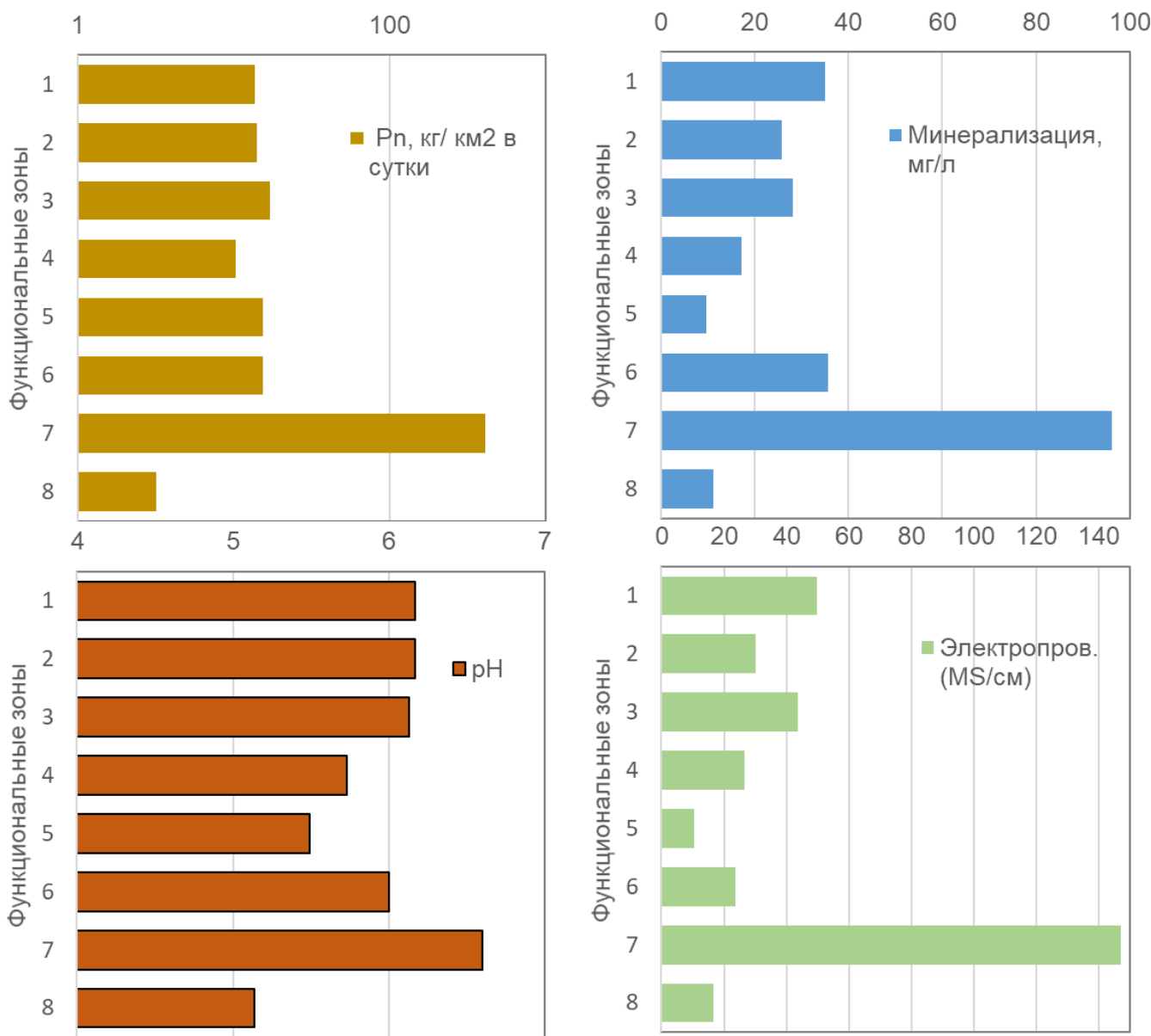

Рис. 2. Значения минерализации, электропроводности рН и пылевой нагрузки в различных функциональных зонах Тобольска. Функииональные зоны: 1 -многоэтажной застройки; 2 -малоэтажной застройки; 3 - общественно-деловая; 4 - промышленная; 5 - коммунально-складская; 6 - историко-культурный иентр; 7 -автотрассы; 8 - фоновые участки

Fig. 2. Mineralization, electrical conductivity, pH and dust load values in different functional zones of Tobolsk. Functional zones: 1 - high-rise buildings; 2 - low-rise buildings; 3 - public and business; 4 - industrial; 5 - communalwarehouse; 6 - historical and cultural center; 7 - highways; 8 -background areas

Основной методический прием изучения загрязнения тяжелыми металлами основан на сопоставлении с показателями местного фона. В районе Тобольска на фоновой территории по значениям кларков концентрации выделяются элементы, концентрирующиеся в твердофазных выпадениях $(3<K K<10)-\mathrm{Ag}, \mathrm{Sn}, \mathrm{Cd}, \mathrm{Pb}, \mathrm{Sb}, \mathrm{Zn}$, слабоконцентрирующиеся $(1,5<K K<3)-\mathrm{Mo}, \mathrm{Bi}, \mathrm{Ni}$, с околокларковыми концентрациями - $\mathrm{Cr}, \mathrm{W}, \mathrm{V}, \mathrm{Cu}$, As и рассеивающиеся $(K P>3)-\mathrm{Fe}, \mathrm{Mn}, \mathrm{Co}, \mathrm{Zr}, \mathrm{Sr}, \mathrm{Ba}, \mathrm{Ti}, \mathrm{Sc}, \mathrm{Ga}, \mathrm{Al}, \mathrm{Li}$ и др. (табл. 1). Таким образом, пылевые выпадения на фоновых участках характеризуются повышенным содержанием халькофильных элементов. Концентрация литофильных и сидерофильных элементов, как правило, на уровне кларка либо ниже его в несколько раз.

Значения коэффициента обогащения пылеаэрозолей представлены на рис. 3. КО используется для оценки генезиса элементов. Считается, что значения
$K O<10$ свидетельствуют о формировании пылеаэрозолей под влиянием природных источников, при значениях КО 10-100 пылеаэрозоли имеют смешанное, как природное, так и антропогенное, происхождение, $K O>100$ индицирует антропогенное загрязнение [38]. Обращают на себя внимание высокие значения $K O$ халькофильных элементов ( $\mathrm{Ag}, \mathrm{Cd}, \mathrm{Pb}, \mathrm{Mo})$, которые на фоновой территории выше, чем в городе (рис. 3).

На фоновой территории у всех халькофильных элементов, кроме $\mathrm{Hg}$, значения $K O>10$. Следовательно, они поступают, хотя бы частично, из техногенных источников. Влияют техногенные источники на поступление сидерофильных $\mathrm{Cr}, \mathrm{Ni}, \mathrm{Mo}$. Все литофильные элементы отличаются низкими значениями $K O$. Примечательно, что в составе макроэлементов содержание серы превышает содержание $\mathrm{Na}, \mathrm{K}, \mathrm{P}$ (табл. 1), что не соответствует кларковому ряду. 
Известия Томского политехнического университета. Инжиниринг георесурсов. 2021. Т. 332. № 5. 156-169 Московченко Д.В., Пожитков Р.Ю., Соромотин А.В. Геохимическая характеристика снежного покрова г. Тобольск

Таблица 1. Содержание макро- и микроэлементов в снежной пыли Тобольска и прилегающей фоновой территории, мг/кг (Na, $\mathrm{Mg}, \mathrm{Al}, \mathrm{K}, \mathrm{Ca}, \mathrm{Fe}, \%)$

Table 1. Macro- and microelement concentrations of snow dust deposition in Tobolsk city and the surrounding background area, $\mathrm{mg} / \mathrm{kg}(\mathrm{Na}, \mathrm{Mg}, \mathrm{Al}, \mathrm{K}, \mathrm{Ca}, \mathrm{Fe}, \%)$

\begin{tabular}{|c|c|c|c|c|c|c|c|c|c|c|}
\hline \multirow{2}{*}{$\begin{array}{c}\text { Эле- } \\
\text { мент } \\
\text { Element }\end{array}$} & \multicolumn{5}{|c|}{ Город/City, n=24 } & \multicolumn{5}{|c|}{ Фон/Background, n=7 } \\
\hline & $\begin{array}{c}\text { Cp. геoм. } \\
\text { Geom. mean }\end{array}$ & $\min$ & $\max$ & KK & KP & $\begin{array}{c}\text { Cp. геом. } \\
\text { Geom. mean }\end{array}$ & $\min$ & $\max$ & KK & КР \\
\hline $\mathrm{Li}$ & 5,4 & 0,78 & 20,1 & - & 6,1 & 3,3 & 1,8 & 6,5 & - & 10,1 \\
\hline $\mathrm{Be}$ & 0,52 & 0,15 & 1,6 & - & 4,4 & 0,39 & 0,25 & 0,62 & - & 5,9 \\
\hline $\mathrm{Na}$ & 0,33 & 0,099 & 1,00 & 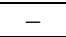 & 6,2 & 0,14 & 0,075 & 0,26 & 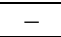 & 14,4 \\
\hline $\mathrm{Mg}$ & 2,76 & 0,14 & 10,03 & 1,6 & - & 0,84 & 0,16 & 2,21 & - & 2,1 \\
\hline $\mathrm{Al}$ & 1,49 & 0,16 & 5,60 & - & 5,1 & 0,76 & 0,36 & 18,2 & - & 10,0 \\
\hline $\mathrm{Fe}$ & 1,83 & 0,16 & 39,3 & - & 2,2 & 0,90 & 0,36 & 2,03 & - & 4,5 \\
\hline $\mathrm{P}$ & 326 & 76 & 1167 & - & 2,1 & 455 & 225 & 1467 & - & 1,5 \\
\hline $\mathrm{S}$ & 1251 & 612 & 1772 & - & 1,1 & 2489 & 1963 & 2894 & 1,8 & - \\
\hline $\mathrm{K}$ & 0,39 & 0,086 & 1,46 & - & 5,8 & 0,23 & 0,13 & 0,42 & - & 9,8 \\
\hline $\mathrm{Ca}$ & 0,54 & 0,051 & 2,24 & - & 7,1 & 0,29 & 0,046 & 0,80 & - & 13,5 \\
\hline $\mathrm{Sc}$ & 4,1 & 0,76 & 10,8 & - & 3,8 & 1,2 & 0,7 & 3,7 & - & 19,5 \\
\hline $\mathrm{Ti}$ & 1064 & 176 & 3947 & - & 3,7 & 199 & 17 & 1248 & - & 19,6 \\
\hline $\mathrm{Mn}$ & 339 & 68 & 643 & - & 2,3 & 115 & 41 & 270 & - & 6,7 \\
\hline $\mathrm{V}$ & 22,1 & 2,54 & 97,1 & - & 4,8 & 37 & 20 & 70 & - & 2,9 \\
\hline $\mathrm{Cr}$ & 274 & 65 & 1313 & 3,0 & & 145 & 76 & 288 & 1,6 & - \\
\hline Co & 14,4 & 1,07 & 42,0 & - & 1,0 & 5,0 & 1,8 & 11,6 & - & 3,0 \\
\hline $\mathrm{Ni}$ & 262 & 33 & 865 & 5,2 & - & 120 & 54 & 258 & 2,4 & - \\
\hline $\mathrm{Zn}$ & 428 & 125 & 1465 & 5,7 & - & 236 & 176 & 375 & 3,1 & - \\
\hline $\mathrm{Cu}$ & 70 & 20 & 188 & 2,6 & - & 52 & 30 & 111 & 1,9 & - \\
\hline As & 7,8 & 0,25 & 27,8 & 1,4 & - & 5,3 & 0,7 & 17,3 & 1,0 & - \\
\hline $\mathrm{Zr}$ & 28,7 & 7,9 & 98,9 & - & 5,6 & 18,0 & 9,8 & 50,6 & - & 8,9 \\
\hline $\mathrm{Ga}$ & 2,9 & 0,23 & 11,3 & - & 6,6 & 2,7 & 1,3 & 9,4 & - & 7,1 \\
\hline $\mathrm{Sr}$ & 43,3 & 8,3 & 138,8 & - & 6,2 & 24,6 & 13,2 & 55,7 & - & 11,0 \\
\hline $\mathrm{Rb}$ & 14,9 & 1,6 & 56,3 & - & 6,6 & 7,9 & 4,1 & 19,7 & - & 12,4 \\
\hline $\mathrm{Y}$ & 4,4 & 1,1 & 16,1 & - & 5,9 & 2,5 & 1,3 & 5,4 & - & 10,3 \\
\hline $\mathrm{Nb}$ & 2,5 & 0,62 & 10,0 & - & 4,9 & 2,1 & 1,4 & 3,7 & - & 5,8 \\
\hline Mo & 1,4 & 0,49 & 2,3 & 1,3 & - & 2,8 & 2,2 & 3,3 & 2,5 & - \\
\hline $\mathrm{Ag}$ & 0,2 & 0,07 & 0,7 & 4,6 & - & 1,9 & 1,2 & 3,8 & 35,6 & - \\
\hline $\mathrm{Cd}$ & 0,7 & 0,13 & 1,4 & 8,2 & - & 0,56 & 0,29 & 1,69 & 6,2 & - \\
\hline Sn & 3,8 & 1,31 & 9,2 & 1,5 & - & 22,6 & 8,0 & 73,7 & 9,0 & - \\
\hline $\mathrm{Sb}$ & 2,9 & 1,14 & 9,5 & 3,6 & - & 2,7 & 1,5 & 5,7 & 3,3 & - \\
\hline Cs & 0,7 & 0,09 & 2,9 & - & 7,7 & 0,4 & 0,2 & 1,2 & - & 12,5 \\
\hline $\mathrm{Ba}$ & 137 & 24 & 443 & - & 3,7 & 67 & 32 & 154 & - & 7,6 \\
\hline W & 2,7 & 0,57 & 8,3 & 1,3 & - & 1,21 & 0,25 & 2,4 & - & 1,7 \\
\hline $\mathrm{La}$ & 7,1 & 1,9 & 22,5 & - & 4,5 & 5,4 & 3,3 & 15,0 & - & 5,9 \\
\hline $\mathrm{Hg}$ & 0,014 & 0,001 & 0,1 & 0,22 & 4,6 & 0,022 & 0,013 & 0,045 & - & 2,9 \\
\hline $\mathrm{Pb}$ & 59 & 11,2 & 157 & 3,5 & - & 83,7 & 30,2 & 326,8 & 4,9 & - \\
\hline $\mathrm{Tl}$ & 0,09 & 0,02 & 0,3 & ND & & 0,060 & 0,038 & 0,116 & - & 12,8 \\
\hline $\mathrm{Bi}$ & 0,4 & 0,08 & 3,7 & 1,9 & - & 0,57 & 0,32 & 1,3 & 2,5 & - \\
\hline Th & 1,5 & 0,27 & 5,1 & - & 6,3 & 0,69 & 0,36 & 1,6 & - & 13,1 \\
\hline $\mathrm{U}$ & 0,7 & 0,20 & 2,1 & - & 3,5 & 0,34 & 0,15 & 0,93 & - & 7,3 \\
\hline
\end{tabular}

\section{Ко}

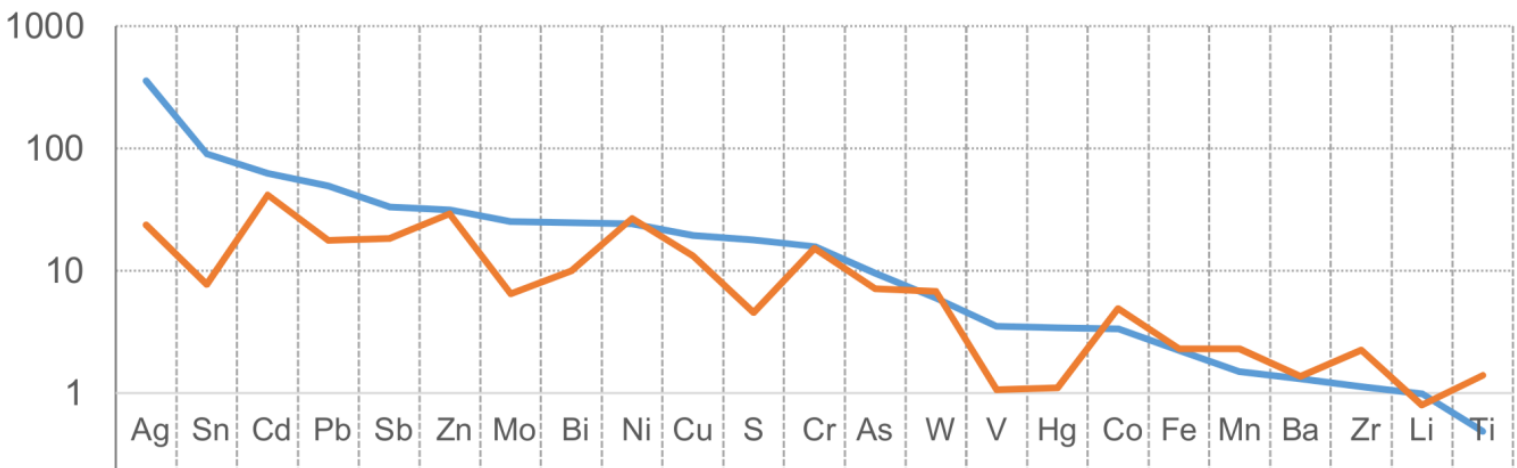

0

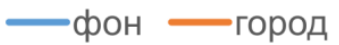

Рис. 3. Значения коэффициентов обогащения снежной пыли на фоновой и урбанизированной территориях

Fig. 3. Values of the enrichment factors for snow dust in the background and urbanized areas 
Преобладание халькофильных элементов в аэротехногенных потоках рассеяния неоднократно описано в научной литературе. Согласно В.В. Добровольскому [39], максимальные коэффициенты аэрозольной концентрации свойственны $\mathrm{Cd}, \mathrm{Pb}, \mathrm{Sn}, \mathrm{Zn}, \mathrm{Cu}, \mathrm{Ni}$. Изучение снега на фоновых участках Подмосковья показало концентрирование $\mathrm{Zn}, \mathrm{Cd}, \mathrm{Sb}, \mathrm{Pb}$ в твердофазной составляющей [17]. В Западной Сибири сделан вывод о максимальных значениях $K O$ для $\mathrm{Sb}, \mathrm{Zn}$, $\mathrm{Cd}$ и As [40]. Сходные значения, подтверждающие доминирование халькофильных элементов в составе пылеаэрозолей, получены и зарубежными исследователями. В атмосферных осадках Пекина элементы по величине коэффициента обогащения образуют следующий ряд: $\mathrm{Cd}, \mathrm{As}, \mathrm{Zn}, \mathrm{Pb}, \mathrm{Cu}$ [41], в расположенном поблизости Тяньцзинье значения $K O$ для снега убывают в последовательности $\mathrm{Se}, \mathrm{Hg}, \mathrm{Cd}, \mathrm{Zn}, \mathrm{As}, \mathrm{Cu}$, $\mathrm{Ni}, \mathrm{Pb}$ [42], на территории Тегерана - в последовательности $\mathrm{Cd}, \mathrm{Zn}, \mathrm{Pb}, \mathrm{Cu}, \mathrm{Ni}$ [43]. В снеге отдаленных районов Тибета были отмечены значения $K O>100$ для $\mathrm{Zn}$ and $\mathrm{Cd}$ [44]. Таким образом, на фоновых участках в районе Тобольска пылеаэрозоли характеризуются накоплением халькофильных элементов, которые распространяются в глобальном масштабе - $\mathrm{Cd}, \mathrm{Zn}$, $\mathrm{Pb}$, As. Обогащение $\mathrm{Sn}$ и Ag ранее не отмечалось, но эти элементы редко исследуются и отсутствие их в списках техногенных загрязнителей вызвано слабой изученностью. Крайне высокое значение $K O$ для $\mathrm{Ag}$, возможно, связано с поступлением этого элемента при горении древесины. Лесные пожары указаны в качестве крупного источника $\mathrm{Ag}$, превышающего ветровую эрозию по объемам поступления [45].

Пониженные значения $K O$ для многих элементов в городе по сравнению с фоном (рис. 3), при внешней парадоксальности такого явления, имеют вполне простое объяснение. Снижение коэффициента обогащения для $\mathrm{Ag}, \mathrm{Sn}, \mathrm{Pb}, \mathrm{Sb}, \mathrm{Mo}, \mathrm{Hg}, \mathrm{V}$ свидетельствует о различном генезисе пылеаэрозолей. $\mathrm{Hg}, \mathrm{Pb}$ или $\mathrm{V}$ могут переноситься в атмосфере на большие расстояния $\left(10^{2}-10^{3}\right.$ км) в ультрадисперсных аэрозолях [46]. Если на фоновых участках пылеаэрозоли поступают в результате дальнего межрегионального переноса частиц микронного и субмикронного размера, состав которых в значительной степени формируется в удаленных от Тобольска промышленных районах, то в городе увеличивается роль крупных частиц местного терригенного происхождения с высоким содержанием литофильных элементов, в том числе используемого для вычисления $K O$ алюминия. Поэтому соотношение $\mathrm{C}_{\text {элемент }} / \mathrm{C}_{\mathrm{Al}}$ в городе уменьшается, и соответственно $K O$ снижается по сравнению с фоном.

Абсолютные концентрации химических элементов в пылевых выпадениях по сравнению с фоном возрастают в несколько раз. Наиболее существенно увеличивается содержание Ті (среднее значение $K c=5,3$ ), Mg (3,3), Mn (3,0) Co $(2,9)$ Ni $(2,6)$, W $(2,2)$. Содержание остальных металлов близко к фоновым значениям. Максимальные значения $K c$ для $\mathrm{Ti}, \mathrm{Mn}, \mathrm{Fe}$ свидетельствуют о преобладании эрозионно-почвенного источника пылеаэрозолей в городе. Основным техногенным источником Ті является сжигание угля на электростанциях и производство цемента [47], однако Тобольская ТЭЦ в качестве топлива использует природный газ и не является источником поступления этого элемента, поскольку в промышленной зоне концентрация Ті не превышает средние для города значения.

Среднее содержание макроэлементов в твердофазных выпадениях на территории Тобольска образует ряд $\mathrm{Mg}>\mathrm{Fe}>\mathrm{Al}>\mathrm{Ca}>\mathrm{K}>\mathrm{Na}>\mathrm{S}>\mathrm{Ti}>\mathrm{Mn}>\mathrm{P}$, в котором последовательность элементов по сравнению с кларковым рядом отличается повышенным содержанием $\mathrm{Mg}$ и S. На фоновых участках среднее содержание $\mathrm{Mg}$ $(0,84 \%)$ соответствует содержанию в пойменных почвах нижнего течения Иртыша, где по данным [48] варьирует от 0,4 до 1,57 \%. На территории города содержание $\mathrm{Mg}$ увеличивается в 3,3 раза. Мелкодисперсная (илистая и глинистая) фракция ветроэродируемых почв и отложений обычно содержит более высокие концентрации металлов, чем основная почва или материнские породы, из которых они получены, благодаря большой удельной площади поверхности мелких частиц, что способствует поглощению ионов металлов или присутствию органических веществ, с которыми часто связаны ионы металлов [49].

Значения $K c$ для большинства элементов сильно варьируют по территории города, что связано с многообразием источников выбросов. В зонах, где велико влияние автотранспорта (возле автомагистралей и в общественно-деловой), наблюдается обогащение пылеаэрозолей $\mathrm{Co}, \mathrm{W}, \mathrm{Ni}$. Поступление $\mathrm{W}$ и Со связано с металлоабразивными пылями [7], что говорит о поступлении этих элементов при истирании металлических деталей автотранспорта. Ni в повышенных количествах содержится в нефти и продуктах ее переработки.

В зоне многоэтажной застройки, где отмечены максимальные значения суммарного показателя загрязнения $Z c$ (табл. 2), в геохимическую ассоциацию загрязнителей входят $\mathrm{Ti}, \mathrm{Zn}, \mathrm{Bi}, \mathrm{Ni}, \mathrm{Co}$. Присутствие в ассоциации загрязнителей Ni свидетельствует о влиянии транспорта. Ві поступает в окружающую среду при производстве стройматериалов [7].

Значения суммарного показателя загрязнения $Z c$ во всех пунктах опробования $<32$, что соответствует низкому неопасному уровню загрязнения. Максимальные значения Zc (28-31) отмечены в пробах, отобранных в центре города. Резкого различия в уровне загрязненности различных функциональных зон не выявлено.

Как показал кластерный анализ, в пылеаэрозолях города выделяются три геохимических ассоциации. Наиболее тесная связь характерна для ассоциации литофильных элементов Li, Ti, Rb, Be, Sr, Y, Ba, La, Th, $\mathrm{U}$ (рис. 4). В данную ассоциацию входят элементы, в значительных количествах поступающие с крупной терригенной пылью. Во вторую ассоциацию входят халькофильные $\mathrm{Cu}$, Sn, Mo As $\mathrm{Cd}, \mathrm{Ag}, \mathrm{Sb}$. Халькофильные элементы (Pb, Cd, As) образуют ассоциации с газообразными компонентами (сульфатами) [50]. Отмеченный ранее факт обогащения пылеаэрозолей на фоновых участках халькофильными элементами 
дает основания для предположения о поступлении их преимущественно с мелкодисперсными частицами путем трансрегионального переноса. В третью ассоциацию входят $\mathrm{W}, \mathrm{Co}, \mathrm{Ni}, \mathrm{Mn}, \mathrm{Sc}$ - элементы, кото- рые осаждаются вблизи автомагистралей. Поэтому данную ассоциацию можно считать индикатором влияния автотранспорта.

Таблица 2. Показатели концентрирования ТМ и металлоидов в снежной пыли функциональных зон Тобольска (суммарный показатель загрязнения Zc и коэффищиент концентращии Kc)

Table 2. Indicators of concentration of trace metals and metalloids in snow dust of functional zones of Tobolsk city (total contamination index $Z c$ and concentration coefficient $K c)$

\begin{tabular}{|c|c|c|c|c|}
\hline $\begin{array}{l}\text { Функциональные зоны } \\
\text { Land use type }\end{array}$ & $Z c$ & $K c=5,1-10$ & $3,1-5$ & $1,5-3$ \\
\hline $\begin{array}{l}\text { Многоэтажной застройки } \\
\text { High-rise residential area }\end{array}$ & 29 & $\mathrm{Ti}_{5,6}$ & $\mathrm{Zn}_{4,0} \mathrm{Bi}_{3,9} \mathrm{Ni}_{3,4} \mathrm{Co}_{3,2}$ & $\mathrm{Mn}_{3,0} \mathrm{Be}_{2,9} \mathrm{~W}_{2,3} \mathrm{Fe}_{2,3} \mathrm{As}_{2,2} \mathrm{Cr}_{2,1} \mathrm{Sr}_{1,9} \mathrm{Cu}_{1,9} \mathrm{~V}_{1,8} \mathrm{Sb}_{1,6} \mathrm{Cd}_{1,5}$ \\
\hline $\begin{array}{l}\text { Малоэтажной застройки } \\
\text { Low-rise residential area }\end{array}$ & 23 & - & $\mathrm{Ti}_{4,3} \mathrm{Zn}_{3,5} \mathrm{Co}_{3,5}$ & $\mathrm{Ni}_{2,9} \mathrm{Be}_{2,9} \mathrm{Mn}_{2,8} \mathrm{Cr}_{2,5} \mathrm{Fe}_{2,4} \mathrm{~W}_{2,2} \mathrm{As}_{2,0} \mathrm{Sb}_{2,0} \mathrm{Cu}_{1,9} \mathrm{Sr}_{1,9} \mathrm{Cd}_{1,5}$ \\
\hline $\begin{array}{l}\text { Историко-культурный центр } \\
\text { Historical center }\end{array}$ & 10 & $\mathrm{Ti}_{5,4}$ & - & $\mathrm{As}_{2,4} \mathrm{Mn}_{2,2} \mathrm{Sr}_{1,9} \mathrm{Co}_{1,8}$ \\
\hline $\begin{array}{l}\text { Автомагистрали } \\
\text { Transport area }\end{array}$ & 21 & - & $\mathrm{Co}_{3,9}$ & $\mathrm{~W}_{3,0} \mathrm{Ti}_{2,9} \mathrm{Ni}_{2,9} \mathrm{Mn}_{2,0} \mathrm{Cr}_{2,0} \mathrm{Fe}_{1,5}$ \\
\hline $\begin{array}{l}\text { Общественно-деловая } \\
\text { Public and business area }\end{array}$ & 18 & - & $\mathrm{Co}_{4,5} \mathrm{Ti}_{4,0} \mathrm{Ni}_{3,9} \mathrm{~W}_{3,4}$ & $\mathrm{Mn}_{2,8} \mathrm{Fe}_{2,2} \mathrm{Cr}_{2,2} \mathrm{As}_{1,7} \mathrm{Zn}_{1,6}$ \\
\hline $\begin{array}{l}\text { Коммунально-складская } \\
\text { Communal warehouse area }\end{array}$ & 16 & - & $\mathrm{Ti}_{4,5}$ & $\mathrm{Mn}_{2,7} \mathrm{Co}_{2,4} \mathrm{Ni}_{2,3} \mathrm{~W}_{2,2} \mathrm{As}_{2,1} \mathrm{Fe}_{1,8} \mathrm{Sr}_{1,8} \mathrm{Cd}_{1,7} \mathrm{Be}_{1,7} \mathrm{Cr}_{1,6} \mathrm{Zn}_{1,6}$ \\
\hline $\begin{array}{l}\text { Промзона } \\
\text { Industrial area }\end{array}$ & 16 & - & $\mathrm{Ti}_{3,8} \mathrm{Cr}_{3,2}$ & $\mathrm{Mn}_{2,6} \mathrm{Sr}_{2,5} \mathrm{Zn}_{2,5} \mathrm{As}_{2,4} \mathrm{Co}_{2,2} \mathrm{~W}_{1,9} \mathrm{Be}_{1,8} \mathrm{Fe}_{1,8} \mathrm{Ni}_{1,7}$ \\
\hline
\end{tabular}

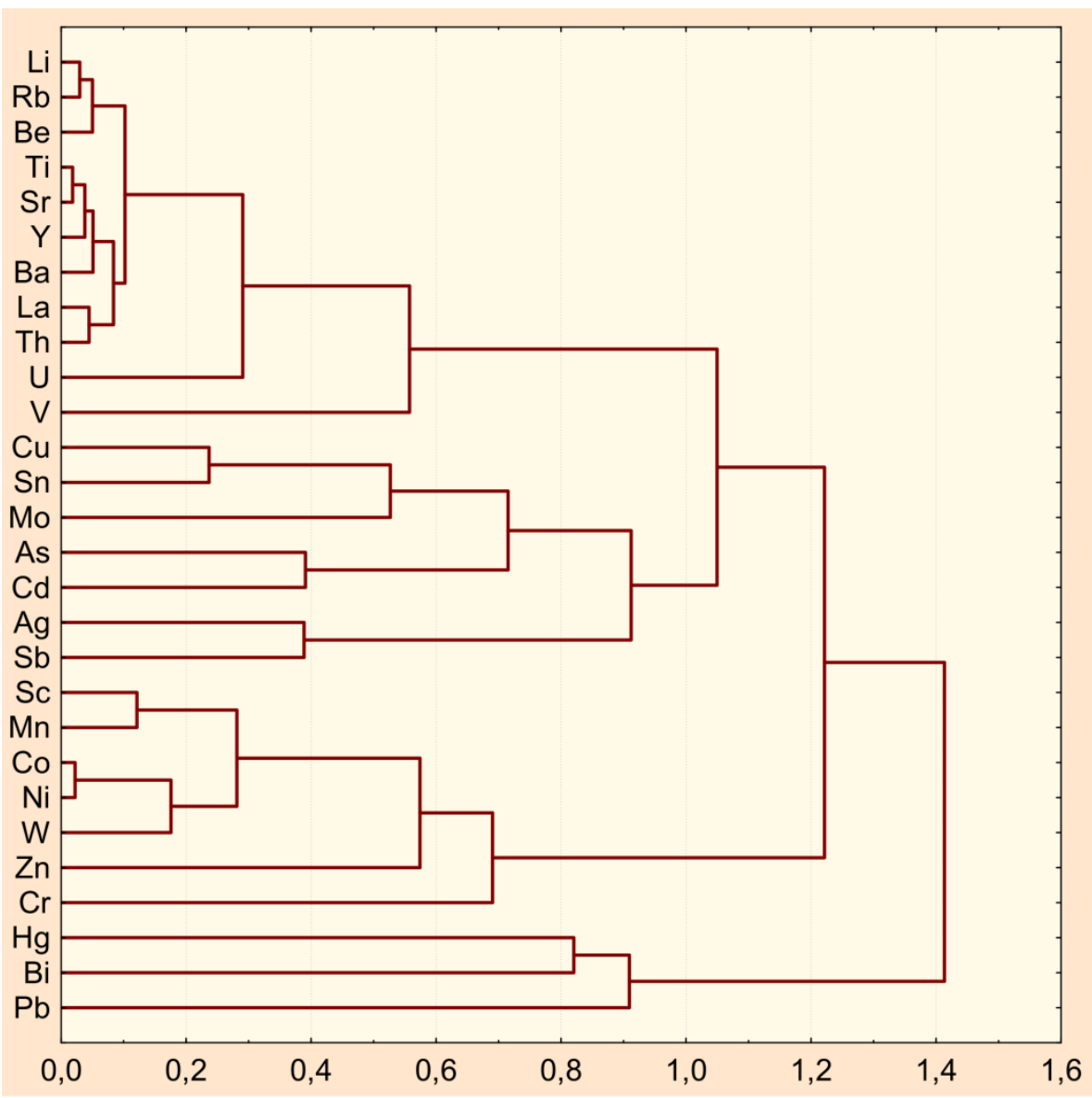

Рис. 4. Дендрограмма кластерного анализа выпадений микроэлементов на территории Тобольска. Метод наиболее удаленных соседей, мера сходства 1-r

Fig. 4. Dendrogram of cluster analysis of microelement deposition in Tobolsk city. Amalgamation (joining) rule: Complete Linkage. Distance metric is 1-Pearson $r$

Значения суммарного показателя имиссии $Z d$ на территории Тобольска изменяются на два математических порядка, достигая в максимуме 4083 (табл. 3).
Однако почти во всех пунктах наблюдений $Z d<1000$, что соответствует низкому уровню загрязнения. Только на участке с интенсивным движением транс- 
порта, на пересечении двух транспортных потоков федеральной автотрассы Тюмень-Сургут и дороги, соединяющей жилую зону Тобольска с промышленной, отмечен очень высокий уровень загрязнения $(Z d=4000-8000)$. Высокое значение $Z d$ объясняется здесь крайне высокой пылевой нагрузкой, превышающей 400 кг/км ${ }^{2}$ в сутки. В зоне многоэтажной застройки, где проживает основная часть населения Тобольска, интенсивность выпадения ТМ невелика $(Z d=185)$. Незначительная величина имиссии связана с относительно малым количеством пылевых выпадений и невысокой концентрацией металлов и металло- идов. Примечательно, что в промышленной зоне имиссия загрязнителей меньше, чем в жилой зоне. На территории промзоны был отмечен довольно большой разброс значений $Z d$ - от 7 до 543, причем максимальное значение отмечено на участке с интенсивным движением транспорта, а минимальное - на площадке возле ЛЭП, вдали от автодорог. Таким образом, деятельность предприятий Тобольской промзоны приводит лишь к незначительному росту пылевых выпадений и поступления ТМ, количество которых не превышает показателей в других функциональных зонах города.

Таблица 3. Величины коэффициентов превышения выпадений ТМ и металлоидов над фоном Кд и суммарного показателя имиссии элементов $Z d$ в различных функииональных зонах Тобольска

Table 3. Values of the coefficient of of trace metals and metalloids deposition excess over the background Kd and the total imission index $\mathrm{Zd}$ in different functional zones of Tobolsk city

\begin{tabular}{|c|c|c|c|c|c|}
\hline $\begin{array}{l}\text { Функциональные зоны } \\
\text { Functional zones } \\
\end{array}$ & $\mathrm{Zd}$ & $\mathrm{Kd}>25$ & $\mathrm{Kd}=25-10$ & $\mathrm{Kd}=10-5$ & $\mathrm{Kd}<5$ \\
\hline $\begin{array}{l}\text { Многоэтажной застройки } \\
\text { High-rise buildings }\end{array}$ & 185 & $\mathrm{Ti}_{35,0}$ & $\begin{array}{c}\mathrm{Co}_{20,0} \mathrm{Mn}_{18,5} \mathrm{Ni}_{14,3} \\
\mathrm{Fe}_{13,1} \mathrm{~W}_{11,6} \mathrm{Zn}_{11,0} \\
\mathrm{Sr}_{10,5} \mathrm{As}_{10,0} \\
\end{array}$ & $\begin{array}{c}\mathrm{Cr}_{9,7} \mathrm{Cu}_{8,8} \mathrm{Cd}_{8,1} \\
\mathrm{Be}_{7,8} \mathrm{Sb}_{6,8} \mathrm{Bi}_{6,4} \mathrm{~V}_{5,5}\end{array}$ & $\mathrm{~Pb}_{4,1}$ \\
\hline $\begin{array}{l}\text { Малоэтажной застройки } \\
\text { Low-rise buildings }\end{array}$ & 162 & - & $\begin{array}{c}\mathrm{Ti}_{24,7} \mathrm{Co}_{23,2} \mathrm{Ni}_{17,6} \\
\mathrm{Mn}_{14,6} \mathrm{~W}_{13,6} \mathrm{Cr}_{11,7} \\
\mathrm{Zn}_{11,5}\end{array}$ & $\begin{array}{c}\mathrm{Fe}_{9,5} \mathrm{Sr}_{8,4} \mathrm{Cd}_{7,6} \mathrm{Cu}_{7,5} \\
\mathrm{As}_{6,0} \mathrm{Be}_{5,8} \mathrm{Sb}_{5,7}\end{array}$ & $\mathrm{~Pb}_{4,1} \mathrm{~V}_{3,1} \mathrm{Bi}_{3,0}$ \\
\hline $\begin{array}{l}\text { Историко-культурный } \\
\text { центр } \\
\text { Historical and cultural center }\end{array}$ & 50 & - & $\mathrm{Ti}_{14,4}$ & $\mathrm{As}_{6,4} \mathrm{Mn}_{5,8} \mathrm{Sr}_{5,0}$ & $\begin{array}{c}\mathrm{Co}_{4,9} \mathrm{Fe}_{3,9} \mathrm{~W}_{3,6} \mathrm{Be}_{3,2} \\
\mathrm{Cd}_{3,0} \mathrm{Cu}_{3,0} \mathrm{Ni}_{2,9} \\
\mathrm{Zn}_{2,0} \mathrm{~V}_{1,9} \mathrm{Cr}_{1,8} \mathrm{~Pb}_{1,7}\end{array}$ \\
\hline $\begin{array}{l}\text { Автомагистрали } \\
\text { Transport area }\end{array}$ & 4083 & $\begin{array}{c}\mathrm{Co}_{720} \mathrm{~W}_{572} \mathrm{Ni}_{550} \mathrm{Ti}_{530} \mathrm{Mn}_{418} \\
\mathrm{Cr}_{378} \mathrm{Fe}_{285} \mathrm{Sr}_{174} \mathrm{Be}_{82} \mathrm{Zn}_{74} \\
\mathrm{~V}_{67} \mathrm{Sb}_{64} \mathrm{As}_{58} \mathrm{Cu}_{48} \mathrm{Cd}_{43}\end{array}$ & $\mathrm{Bi}_{18} \mathrm{~Pb}_{17}$ & - & 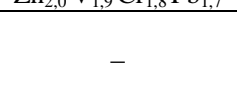 \\
\hline $\begin{array}{l}\text { Общественно-деловая } \\
\text { Public and business area }\end{array}$ & 233 & $\mathrm{Co}_{34,8} \mathrm{Ti}_{31,4} \mathrm{Ni}_{30,4} \mathrm{~W}_{26,3}$ & $\begin{array}{c}\mathrm{Mn}_{22,2} \mathrm{Fe}_{17,4} \mathrm{Cr}_{17,0} \\
\mathrm{As}_{11,4} \mathrm{Zn}_{10,0} \\
\end{array}$ & $\begin{array}{c}\mathrm{Cd}_{9,2} \mathrm{Sr}_{9,0} \mathrm{Cu}_{6,7} \\
\mathrm{Be}_{6,0} \mathrm{~V}_{5,9} \mathrm{Sb}_{5,6} \\
\end{array}$ & $\mathrm{Bi}_{3,4} \mathrm{~Pb}_{2,6}$ \\
\hline $\begin{array}{l}\text { Коммунально-складская } \\
\text { Communal warehouse area }\end{array}$ & 151 & $\mathrm{Ti}_{32,1}$ & $\begin{array}{l}\mathrm{Mn}_{12,9} \mathrm{Co}_{12,6} \mathrm{~W}_{11,7} \\
\mathrm{Sr}_{10,8} \mathrm{Fe}_{10,5} \mathrm{As}_{10,1}\end{array}$ & $\begin{array}{c}\mathrm{Be}_{9,4} \mathrm{Ni}_{8,1} \mathrm{Cr}_{7,9} \mathrm{Zn}_{7,5} \\
\mathrm{Sb}_{6,6} \mathrm{Cu}_{6,3} \mathrm{~Pb}_{6,0} \\
\mathrm{Cd}_{5,7}\end{array}$ & $\mathrm{~V}_{4,3} \mathrm{Bi}_{4,3}$ \\
\hline $\begin{array}{l}\text { Промзона } \\
\text { Industrial area }\end{array}$ & 132 & - & $\begin{array}{c}\mathrm{Ti}_{17,8} \mathrm{Mn}_{15,4} \mathrm{Co}_{13,0} \\
\mathrm{Zn}_{12,2} \mathrm{As}_{12}\end{array}$ & $\begin{array}{l}\mathrm{Ni}_{9,2} \mathrm{Fe}_{8,9} \mathrm{Cr}_{8,7} \mathrm{Sr}_{7,9} \\
\mathrm{Be}_{7,5} \mathrm{~W}_{7,0} \mathrm{Cd}_{6,6} \mathrm{~V}_{6,3} \\
\end{array}$ & $\mathrm{Cu}_{4,8} \mathrm{Bi}_{3,7} \mathrm{Sb}_{3,7} \mathrm{~Pb}_{2,9}$ \\
\hline
\end{tabular}

\section{Выводы}

1. Минерализация снеготалых вод в среднем в фоновых условиях составляет 11 мг/л, в городе 25 мг/л, резкое увеличение минерализации отмечено вблизи автодорог вследствие использования противогололедных реагентов.

2. Пылевая нагрузка в городе возрастает относительно фона в 4,7 раза, среднее значение 15,2 мг/м² в сутки. Интенсивность пылевых выпадений по сравнению с крупными городами (Москва, Томск, Норильск) низкая. Значительное усиление выпадения пылеаэрозолей - до 406 мг/м² в сутки - наблюдается на участках интенсивного движения автотранспорта.

3. Выявлено типичное для урбоэкосистем подщелачивание снеготалых вод, средняя величина $\mathrm{pH}$ возрастает от 5,1 ед. на фоновых участках до 6,0 ед. в городе.

4. Элементный состав пылеаэрозолей на фоновой территории определяется процессами трансрегионального переноса загрязнителей, что выражается в обогащенности халькофильными элементами $(\mathrm{Ag}, \mathrm{Cd}, \mathrm{Pb}, \mathrm{Sn}, \mathrm{Sb})$. У всех халькофильных эле- ментов, кроме $\mathrm{Hg}$, значение коэффициента обогащения $K O>10$, что говорит о техногенной природе.

5. На территории города ассоциация элементовзагрязнителей включает в себя $\mathrm{Ti}, \mathrm{Mn}, \mathrm{Co}, \mathrm{Ni}, \mathrm{W}$. Максимальные значения коэффициента концентрации $K c$ для $\mathrm{Ti}, \mathrm{Mn}, \mathrm{Fe}$ свидетельствуют о преобладании эрозионно-почвенного источника. Под влиянием автотранспорта наблюдается обогащение пылеаэрозолей $\mathrm{Co}, \mathrm{W}, \mathrm{Ni}$, поступление которых связано с металлоабразивными частицами.

6. Значения суммарного показателя загрязнения $Z c$ во всех пунктах опробования $<32$, что соответствует низкому неопасному уровню загрязнения. Значения суммарного показателя имиссии элементов $Z d$, характеризующего как микроэлементный состав твердофазных выпадений, так и пылевую нагрузку, также соответствуют низкому уровню загрязнения с неопасной экологической ситуацией. Только на участке с интенсивным движением транспорта отмечен очень высокий уровень имиссии элементов.

Работа выполнена при поддержке гранта РФФИ 19-0550062 и проекта фундаментальных исследований СО РАН IX.135.2.2. (Рег. № НИОКТР АAАA-A17-117051850064-0). 


\section{СПИСОК ЛИТЕРАТУРЫ}

1. Федеральная служба государственной статистики. Демография. Численность населения. URL: https://rosstat.gov.ru/folder/ 12781 (дата обращения 08.10.2020).

2. Доклад об экологической ситуации в Тюменской области в 2017 году. Правительство Тюменской области. URL: https://admtyumen.ru/ogv_ru/about/ecology/eco_monitoring/envir onment.htm (дата обращения 08.10.2020).

3. Characteristics of the trace elements and arsenic, iodine and bromine species in snow in east-central China / Y. Gao, C. Yang, J. Ma, M. Yin // Atmospheric Environment. - 2018. - V. 174. P. 43-53. URL: https://doi.org/10.1016/j.atmosenv.2017.11.015 (дата обращения 08.10.2020).

4. Assessment of major ions and trace elements in snow: a case study across northeastern China, 2017-2018 / H. Xue, W. Chen, M. Li, B. Liu, G. Li, X. Han // Chemosphere. - 2020. - V. 251. P. 126328. URL: https://doi.org/10.1016/j.chemosphere.2020.126328 (дата обращения 08.10.2020).

5. Heavy metal concentration and distribution of snow and Lichea samples in urban area: case study of Jelgava / J. Pilecka, I. Grinfelde, K. Valujeva, I. Straupe, O. Purmalis // International Multidisciplinary Scientific GeoConference: SGEM. - 2017. V. 17. - P. 459-466. DOI: $10.5593 /$ sgem2017/41

6. Seasonal comparison of moss bag technique against vertical snow samples for monitoring atmospheric pollution / H. Salo, A.K. Berisha, J. Mäkinen // Journal of Environmental Sciences. - 2016. V. 41. - P. 128-137. URL: https://doi.org/10.1016/j.jes.2015.04.021 (дата обращения 08.10.2020).

7. Геохимия окружающей среды / Ю.Е. Сает, Б.А. Ревич, Е.П. Янин, Р.С. Смирнова, И.Л. Башаркевич, Т.Л. Онищенко Л.Н. Павлова, Н.Я. Трефилова, А.И. Ачкасова, С.Ш. Саркисян. - М.: Недра, 1990. - 335 с.

8. Гвоздецкий Н.А. Физико-географическое районирование Тюменской области. - М.: Изд-во МГУ, 1973. - 246 с.

9. Научно-прикладной справочник по климату СССР. Серия 2. Многолетние данные. Вып. 17. Тюменская и Омская области. - СПб: Гидрометеоиздат, 1998. - 702 с.

10. Официальный сайт администрации города Тобольска. Социально-экономическое развитие города. URL http://admtobolsk.ru/econom/price/ (дата обращения 08.10.2020).

11. Laboratory melting of late-winter urban snow samples: the magnitude and dynamics of releases of heavy metals and PAHs / A. Vijayan, H. Österlund, J. Marsalek, M. Viklander // Water, Air, \& Soil Pollution. - 2019. - V. 230. - № 8. - P. 182. URL: https://doi.org/10.1007/s11270-019-4201-2 (дата обращения 08.10.2020).

12. Lau W.K., Kim K.M. Impact of snow darkening by deposition of light-absorbing aerosols on snow cover in the Himalayas-Tibetan Plateau and influence on the Asian summer monsoon: a possible mechanism for the Blanford hypothesis // Atmosphere. - 2018. V. 9. - № 11. - P. 438. URL: https://doi.org/10.3390/ atmos9110438 (дата обращения 08.10.2020).

13. Atmospheric deposition of organochlorine pesticides and industrial compounds to seasonal surface snow at four glacier sites on Svalbard, 2013-2014 / M.H. Hermanson, E. Isaksson, R. Hann, C. Teixeira, D.C. Muir / Environmental Science \& Technology. 2020. - V. 54. - № 15 - P. 9265-9273. URL: https://doi.org/ 10.1021/acs.est.0c01537 (дата обращения 08.10.2020).

14. Архив погоды в Тюмени. Расписание погоды. URL: https://rt5.ru/ (дата обращения 08.10.2020).

15. Методические рекомендации по геохимической оценке загрязнения территории городов химическими элементами Б.А. Ревич, Ю.Е. Сает, Р.С Смирнова., Е.П. Сорокина. - М.: ИМГРЭ, 1982. - $112 \mathrm{c}$.

16. Касимов Н.С. Экогеохимия городских ландшафтов. - М.: Изд-во Моск. Ун-та, 1995. - $336 \mathrm{c}$

17. Геохимия снежного покрова в восточном округе Москвы Н.С. Касимов, Н.Е Кошелева, Д.В. Власов, Е.В. Терская // Вестн. Моск. ун-та. Сер. 5. География. - 2012. - № 4. - С. 14-24.

18. Григорьев Н.А. Распределение химических элементов в верхней части континентальной коры. - Екатеринбург: УрО РАН, 2009. - 382 c.

19. Регионы и города России: интегральная оценка экологического состояния / Н.С. Касимов, В.Р. Битюкова, С.М. Малхазова,
Н.Е. Кошелева, Е.М. Никифорова, Н.В. Шартова, Д.В. Власов, С.А. Тимонин, В.Н. Крайнов. - М.: ИП Филимонов М.В., 2014. - 560 с. 20. Московченко Д.В., Бабушкин А.Г. Особенности формирования химического состава снегового покрова на территории Ханты-Мансийского автономного округа // Криосфера Земли. -2012 . - T. XVI. - № 1. - C. 71-81.

21. Московченко Д.В. Нефтегазодобыча и окружающая среда: эколого-геохимический анализ Тюменской области. - Новосибирск: Наука, Сиб. предприятие РАН, 1998. - 112 с.

22. Пожитков Р.Ю., Московченко Д.В., Кудрявцев А.А. Геохимия снежного покрова г. Нижневартовска // Вестник Тюменского государственного университета. Экология и природопользование. - 2018. - T. 4. - № 1. - C. 6-24. DOI: 10.21684/24117927-2018-4-1-6-24

23. Дорожукова С.Л. Эколого-геохимические особенности нефтегазодобывающих районов Тюменской области: автореф. дисс. ... канд. геол-минерал. наук. - М., 2004. - 25 с.

24. Свистов П.Ф., Полищук А.И. Атмосферные осадки над городами и регионами России // Природа. - 2014. - № 3 (1183). C. $28-36$.

25. Saharan dust particles in snow samples of Alps and Apennines during an exceptional event of transboundary air pollution / C. Telloli, M. Chicca, S. Pepi, C. Vaccaro // Environmental monitoring and assessment. - 2018. - V. 190. - № 1. - P. 37. URL: http://dx.doi.org/10.1007/s10661-017-6412-6 (дата обращения 08.10.2020).

26. Dust dominates high-altitude snow darkening and melt over highmountain Asia / C. Sarangi, Y. Qian, K. Rittger, L.R. Leung, D. Chand, K.J. Bormann, T.H. Painter // Nature Climate Change. 2020. - P. 1-7. URL: https://doi.org/10.1038/s41558-020-00909-3 (дата обращения 08.10.2020).

27. Atmospheric dust deposition varies by season and elevation in the Colorado Front Range, USA / R.C. Heindel, A.L. Putman, S.F. Murphy, D.A. Repert, E.L. Hinckley // Journal of Geophysical Research: Earth Surface. - 2020. - V. 125. - № 5. P. e2019JF005436. URL: https://doi.org/10.1029/2019JF005436 (дата обращения 08.10.2020).

28. Распределение и состав нерастворимых частиц в снеге Арктики / В.П. Шевченко, А.П. Лисицын, Р. Штайн, Н.В. Горюнова, А.А. Клювиткин, М.Д. Кравчишина, М. Кривс, А.Н. Новигатский, В.Т. Соколов, А.С. Филиппов, Х. Хаас // Проблемы Арктики и Антарктики. - 2007. - № 1 (75). - С. 106-118.

29. Боев В.А., Лежнина А.А. Тяжёлые металлы в снежном покрове Тюменского района Тюменской области // Вестник Тюменского государственного университета. Экология и природопользование. - 2012. - № 7. - С. 41-48.

30. Язиков Е.Г., Таловская А.В., Жорняк Л.В. Оценка экологогеохимического состояния территории г. Томска по данным изучения пылеаэрозолей и почв: монография. - Томск: Изд-во Томского политехнического университета, 2010. - 264 с.

31. Оценка пылевого загрязнения атмосферы г. Омска по данным снеговой съемки / В.В. Литау, А.В. Таловская, Е.Г. Язиков, А.Д. Лончакова, М.И. Третьякова // Оптика атмосферы и океана. - 2015. - Т. 28. - № 3. - С. 256-259.

32. Ермолов Ю.В., Смоленцев Н.Б Зимний фоновый сток примесей атмосферы на юго-востоке Западной Сибири // Оптика атмосферы и океана. - 2020. - Т. 33. - № 1 (372). - С. 75-81. DOI: $10.15372 / \mathrm{AOO} 20200111$

33. Загрязнение снежного покрова в зоне воздействия предприятий Норильского промышленного района / А.А. Онучин, Т.А. Буренина, О.Н. Зубарева, О.В. Трефилова, И.В. Данилова // Сибирский экологический журнал. - 2014. - Т. 21. - № 6. C. $1025-1037$

34. Таловская А.В., Филимоненко Е.А., Язиков Е.Г. Динамика элементного состава снегового покрова на территории северовосточной зоны влияния Томск-Северской промышленной агломерации // Оптика атмосферы и океана. - 2014. - Т. 27. № 6. - С. 491-495.

35. Таловская А.В. Геохимическая характеристика пылевых атмосферных выпадений на территории г. Томска // Оптика атмосферы и океана. - 2010. - Т. 23. - № 6. - С. 519-524.

36. Jarzyna K., Kozłowski R., Szwed M. Chemical properties of snow cover as an impact indicator for local air pollution sources // Infrastructure and Ecology of rural areas. - 2017. - V. 4. - № 2. P. 1591-1607. DOI: http://dx.medra.org/10.14597/infraeco.2017.4.2.120 
37. Факащук Н.Ю., Соромотин А.В. Оценка состояния снежного покрова и почв Тобольской промзоны // Вестник Тюменского государственного университета. Экология и природопользование. - 2017. - T. 3. - № 2. - C. 22-33. DOI: 10.21684/2411 7927-2017-3-2-22-33

38. Concentrations and solubility of trace elements in fine particles at a mountain site, southern China: regional sources and cloud processing / T. Li, Y. Wang, W.J. Li, J.M. Chen, T. Wang, W.X. Wang // Atmospheric Chemistry and Physics. - 2015. V. 15. - P. 8987-9002. DOI: 10.5194/acp-15-89-87-2015

39. Добровольский В.В. География микроэлементов. Глобальное рассеяние. - М.: Мысль, 1983. - 272 с.

40. Impact of snow deposition on major and trace element concentrations and elementary fluxes in surface waters of the Western Siberian Lowland across a $1700 \mathrm{~km}$ latitudinal gradient / V.P. Shevchenko, O.S. Pokrovsky, S.N. Vorobyev, I.V. Krickov, R.M. Manasypov, N.V. Politova, S.G. Kopysov, O.M. Dara Y. Auda, L.S. Shirokova, L.G. Kolesnichenko, V.A. Zemtsov, S.N. Kirpotin // Hydrology and Earth System Sciences. - 2017. V. 21. - P. 5725-5746. URL: https://doi.org/10.5194/hess-215725-2017 (дата обращения 08.10.2020).

41. Guo L., Lyu Y., Yang Y. Concentrations and chemical forms of heavy metals in the bulk atmospheric deposition of Beijing, China // Environmental Science and Pollution Research. - 2017. - V. 24. P. 27356-27365. URL: https://doi.org/10.1007/s11356-017-0324-4 (дата обращения 08.10.2020)

42. Determination of major and trace elements in snow in Tianjin, China: a three-heating-season survey and assessment / G. Wu Q. Wei, C. Sun, J. Gao, L. Pan, L. Guo // Air Quality, Atmosphere \& Health. - 2016. - V. 9. - P. 687-696. URL https://doi.org/10.1007/s11869-015-0375-у (дата обращения 08.10.2020).

43. Study of trace elements in wet atmospheric precipitation in Tehran, Iran / H. Kamani, M. Hoseini, G.H. Safari, J. Jaafari, A.H. Mahvi // Environmental Monitoring and Assessment. 2014. - V. 186. - P. 5059-5067. URL: https://doi.org/10.1007/s10661014-3759-9 (дата обращения 08.10.2020).
44. New insights into trace elements deposition in the snow packs at remote alpine glaciers in the northern Tibetan Plateau, China / Z.W. Dong, S.C. Kang, X. Qin, X.F. Li, D.H. Qin, J.W. Ren // Science of the Total Environment - 2015 - V. 529 - P. 101-113. URL: https://doi.org/10.1016/j.scitotenv.2015.05.065 (дата обращения 08.10.2020).

45. Микроэлементы в атмосфере фоновых районов суши и океана / А.Х. Остромогильский, Ю.А. Анохин, В.А. Ветров, В.А. Петрухин, А.Л. Пословин // Контроль загрязнения природной среды. Обзорная информация. Вып. 2. - Обнинск: Информационный центр ВНИИГМИ-МЦД, 1981. - 42 с.

46. Steinnes E., Friedland A.J. Metal contamination of natural surface soils from long-range atmospheric transport: existing and missing knowledge // Environmental Reviews. - 2006. -V. 14. - № 3. P. 169-186. URL: https://doi.org/10.1139/a06-002 (дата обращения 08.10.2020)

47. Nriagu J.O., Pacyna J.M. Quantitative assessment of worldwide contamination of air, water and soils with trace elements // Nature. - 1988. - V. 333. - P. 134-139.

48. Нечаева Е.Г. Ландшафтно-геохимический анализ динамики таежных геосистем. - Иркутск: Ин-т географии СО АН СССР, 1985. $-210 \mathrm{c}$

49. Metal and arsenic distribution in soil particle sizes relevant to soil ingestion by children / K. Ljung, O. Selinus, E. Otabbong, M. Berglund // Applied Geochemistry. - 2006. - V. 21. P. 1613-1624. URL: https://doi.org/10.1016/j.apgeochem. 2006.05.005 (дата обращения 08.10.2020).

50. Elemental and base anions deposition in the snow cover of northeastern Estonia. The impact of industrial emissions / M. Kaasik, R. Rõõm, O. Røyset, M. Vadset, Ü. Sõukand, K. Tõugu, H. Kaasik // Water, Air, and Soil Pollution. - 2000. - V. 121. - P. 324-366. URL: https://doi.org/10.1023/A:1005239810199 (дата обращения 08.10.2020).

Поступила 12.04.2021 2.

\section{Информация об авторах}

Московченко Д.В., доктор географических наук, главный научный сотрудник, Тюменский научный центр СО РАН, структурное подразделение Институт проблем освоения Севера.

Пожитков P.Ю., младший научный сотрудник, Тюменский научный центр СО РАН, структурное подразделение Институт проблем освоения Севера.

Соромотин A.B., доктор биологических наук, профессор, Институт наук о Земле, Тюменский государственный университет. 
UDC 551.578.46: 550.42

\title{
GEOCHEMICAL CHARACTERISTICS OF SNOW COVER IN TOBOLSK
}

\author{
Dmitriy V. Moskovchenko1, \\ moskovchenko1965@gmail.com
}

Roman Yu. Pozhitkov', pozhitkov-roma@yandex.ru

Andrey V. Soromotin ${ }^{2}$, asoromotin@mail.ru

1 Tyumen scientific center SB RAS,

86, Malygin street, Tyumen, 625026, Russia.

2 Tyumen State University,

6, Volodarsky street, Tyumen, 625003, Russia.

The relevance of this study is associated with the increasing technogenic pollution of highly industrialized urban areas.

The aim of the research is to determine chemical element contents in solid precipitation and identify sources of pollutants.

Materials: background ecosystems and technogenic urboecosytems in different functional zones of the city of Tobolsk.

Methods: ecological-geochemical analyses of snow cover, determination of physicochemical characteristics of snow (pH, electrical conductivity and salinity), contents of dust-aerosol particles in meltwaters and the chemical composition of solid-phase components using inductively coupled plasma mass spectrometry and atomic emission spectrometry, calculations of parameters characterizing the ecological situation (concentration coefficient Kc, total contamination Zc and emission of elements Zd).

Results. The studied meltwaters were characterized by increased alkalinity, salinity and electrical conductivity, which is typical for urboecosystems. The mean daily dust deposition rate of $15,2 \mathrm{mg} / \mathrm{m}^{2}$ in Tobolsk was 4,7 times higher than that in background ecosystems, but lower than those in large industrial cities. Transport is the main source of snow contamination in Tobolsk. Solid precipitation in background ecosystems around Tobolsk was contaminated by chalcophile elements, which originated from submicron particles brought from distant industrial regions. In Tobolsk, the assemblage of contaminants was indicative of influences of soil erosion (Ti and Mn), motorized vehicles (Ni) and abrasion of metal parts (W and $\mathrm{Co}$ ). Rates of dust-aerosol emissions from the city's industrial zone, which includes the Tobolsk petrochemical complex and the power plant, were not significantly higher than those from other functional zones of the city. Based on Zc and Zd indices, pollution levels within the city, except the main transport zone, were defined as low.

\section{Key words:}

Snow cover, dust aerosol, Tobolsk, heavy metals, total pollution.

This work was supported by the Russian Foundation for Basic Research (project no. 19-05-50062) and project of fundamental research of SB RAS IX.135.2.2. (AAAA-A17-117051850064-0).

\section{REFERENCES}

1. Federalnaya sluzhba gosudarstvennoy statistiki. Demografiya. Chislennost naseleniya [Federal state statistics service. Demography. Population size]. Available at: https://rosstat.gov.ru/folder/ 12781 (accessed 8 October 2020).

2. Doklad ob ekologicheskoy situatsii v tyumenskoy oblasti v 2017 godu. Pravitelstvo Tyumenskoy oblasti [The report on the environmental situation in the Tyumen region in 2017. Government of the Tyumen region]. Available at: https://admtyumen.ru/ogv_ru/ about/ecology/eco_monitoring/environment.htm (accessed 8 October 2020).

3. Gao Y., Yang C., Ma J., Yin M. Characteristics of the trace elements and arsenic, iodine and bromine species in snow in eastcentral China. Atmospheric Environment, 2018, vol. 174, pp. 43-53. Available at: https://doi.org/10.1016/j.atmosenv.2017.11.015 (accessed 8 October 2020).

4. Xue H., Chen W., Li M., Liu B., Li G., Han X. Assessment of major ions and trace elements in snow: a case study across northeastern China, 2017-2018. Chemosphere, 2020, vol. 251, pp. 126328. Available at: https://doi.org/10.1016/j.chemosphere.2020.126328 (accessed 8 October 2020).

5. Pilecka J., Grinfelde I., Valujeva K., Straupe I., Purmalis O. Heavy metal concentration and distribution of snow and Lichea samples in urban area: case study of Jelgava. International Multidisciplinary Scientific GeoConference: SGEM, 2017, vol. 17, pp. 459-466. DOI: $10.5593 / \mathrm{sgem} 2017 / 41$
6. Salo H., Berisha A.K., Mäkinen J. Seasonal comparison of moss bag technique against vertical snow samples for monitoring atmospheric pollution. Journal of Environmental Sciences, 2016, vol. 41, pp. 128-137. Available at: https://doi.org/10.1016/ j.jes.2015.04.021 (accessed 8 October 2020).

7. Saet Yu.E., Revich B.A., Yanin E.P., Smirnova R.S., Basharkevich I.L., Onishchenko T.L., Pavlova L.N., Trefilova N.Ya., Achkasova A.I., Sarkisyan S.Sh. Geokhimiya okruzhayushchey sredy [Geochemistry of the environment]. Moscow, Nedra Publ., $1990.335 \mathrm{p}$.

8. Gvozdetskiy N.A. Fiziko-geograficheskoe rayonirovanie Tyumenskoy oblasti [Physical and geographical zoning of the Tyumen region]. Moscow, Moscow State University Publ., 1973. 246 p.

9. Nauchno-prikladnoy spravochnik po klimatu SSSR. Seriya 2. Mnogoletnie dannye. Vyp. 17. Tyumenskaya i Omskaya oblasti [Scientific and applied reference book on the climate of the USSR. Series 2. Multiyear data. Iss. 17. Tyumen and Omsk regions]. StPetersburg, Gidrometeoizdat Publ., 1998. 702 p.

10. Ofitsialny sayt administratsii goroda Tobolska. Sotsialnoekonomicheskoe razvitie goroda [Official website of the Tobolsk city administration. Socio-economic development of the city]. Available at: http://admtobolsk.ru/econom/price/ (accessed 8 October 2020).

11. Vijayan A., Österlund H., Marsalek J., Viklander M. Laboratory melting of late-winter urban snow samples: the magnitude and dynamics of releases of heavy metals and PAHs. Water, Air, \& Soil Pollution, 2019, vol. 230, no 8, pp. 182. Available at: https://doi. org/10.1007/s11270-019-4201-2 (accessed 8 October 2020). 
12. Lau W.K., Kim K.M. Impact of snow darkening by deposition of light-absorbing aerosols on snow cover in the Himalayas-Tibetan Plateau and influence on the Asian summer monsoon: A possible mechanism for the Blanford hypothesis. Atmosphere, 2018, vol. 9 , no 11, pp. 438. Available at: https://doi.org/10.3390/ atmos9110438 (accessed 8 October 2020).

13. Hermanson M.H., Isaksson E., Hann R., Teixeira C., Muir D.C. Atmospheric deposition of organochlorine pesticides and industrial compounds to seasonal surface snow at four glacier sites on Svalbard, 2013-2014. Environmental Science \& Technology, 2020, vol. 54, no. 15, pp. 9265-9273. Available at: https://doi.org/ 10.1021/acs.est.0c01537 (accessed 8 October 2020).

14. Arkhiv pogody v Tyumeni. Raspisanie pogody [Weather archive in Tyumen. Weather schedule]. Available at: https://rt5.ru/ (accessed 8 October 2020).

15. Revich B.A., Saet Yu.E., Smirnova R.S., Sorokina E.P. Metodicheskie rekomendatsii po geokhimicheskoy otsenke zagryazneniya territorii gorodov khimicheskimi elementami [Methodological recommendations for geochemical assessment of urban pollution by chemical elements]. Moscow, IMGRE Publ., 1982. $112 \mathrm{p}$.

16. Kasimov N.S. Ekogeokhimiya gorodskikh landshaftov [Ecogeochemistry of urban landscapes]. Moscow, Moscow State University Publ., 1995. 336 p.

17. Kasimov N.S., Kosheleva N.E., Vlasov D.V., Terskaya E.V. Geochemistry of snow cover within the Eastern district of Moscow. Vestnik Moskovskogo universiteta. Seriya 5, Geografiya, 2012, no. 4, pp. 14-24. In Rus.

18. Grigoryev N.A. Raspredelenie khimicheskikh elementov v verkhney chasti kontinentalnoy kory [Distribution of chemical elements in the upper part of the continental crust]. Ekaterinburg, UrO RAN Publ., 2009. 382 p.

19. Kasimov N.S., Bityukova V.R., Malkhazova S.M., Kosheleva N.E. Nikiforova E.M., Shartova N.V., Vlasov D.V., Timonin S.A., Kraynov V.N. Regiony $i$ goroda Rossii: Integralnaya otsenka ekologicheskogo sostoyaniya [The regions and cities of Russia: integrated environmental assessment]. Moscow, Filimonov M.V. Publ., 2014. $560 \mathrm{p}$.

20. Moskovchenko D.V., Babushkin A.G. Peculiarities of formation of chemical composition of snow waters (on example of KhantyMansi autonomous district). Kriosfera Zemli, 2012, vol. XVI, no. 1, pp. 71-81. In Rus.

21. Moskovchenko D.V. Neftegazodobycha i okruzhayushchaya sreda: ekologo-geokhimicheskiy analiz Tyumenskoy oblasti [Oil and gas production and environment: ecological and geochemical analysis of the Tyumen region]. Novosibirsk, Nauka Publ., Sib. predpriyatie RAN, 1998. $112 \mathrm{p}$

22. Pozhitkov R.Yu., Moskovchenko D.V., Kudryavtsev A.A. Geochemistry of the snow cover of Nizhnevartovsk. Tyumen State University Herald. Natural Resource Use and Ecology, 2018, vol. 4, no. 1, pp. 6-24. In Rus. DOI: 10.21684/2411-7927-2018-4-1-6-24

23. Dorozhukova S.L. Ekologo-geokhimicheskie osobennosti neftegazodobyvayushchikh rayonov Tyumenskoy oblasti. Avtoreferat Dis. Kand. nauk [Ecological and geochemical features of oil and gas producing areas of the Tyumen region. Cand. Diss. Abstract] Moscow, 2004. 25 p.

24. Svistov P.F., Polishchuk A.I. Atmospheric precipitation over cities and regions of Russia. Priroda, 2014, no. 3 (1183), pp. 28-36. In Rus.

25. Telloli C., Chicca M., Pepi S., Vaccaro C. Saharan dust particles in snow samples of Alps and Apennines during an exceptional event of transboundary air pollution. Environmental monitoring and assessment, 2018, vol. 190, no. 1, pp. 37. Available at: http://dx.doi. org/10.1007/s10661-017-6412-6 (accessed 8 October 2020).

26. Sarangi C., Qian Y., Rittger K., Leung L.R., Chand D., Bormann K.J., Painter T.H. Dust dominates high-altitude snow darkening and melt over high-mountain Asia. Nature Climate Change, 2020, pp. 1-7. Available at: https://doi.org/10.1038/s41558-020-00909-3 (accessed 8 October 2020).

27. Heindel R.C., Putman A.L., Murphy S.F., Repert D.A., Hinckley E.L. Atmospheric dust deposition varies by season and elevation in the Colorado Front Range, USA. Journal of Geophysical Research: Earth Surface, 2020, vol. 125, no. 5, pp. e2019JF005436. Available at: https://doi.org/10.1029/2019JF005436 (accessed 8 October 2020).
28. Shevchenko V.P., Lisicyn A.P., Shtayn R., Goryunova N.V., Klyuvitkin A.A., Kravchishina M.D., Krivs M., Novigatskiy A.N., Sokolov V.T., Filippov A.S., Haas H. Distribution and composition of insoluble particles in Arctic snow. Problemy Arktiki $i$ Antarktiki, 2007, no. 1 (75), pp. 106-118. In Rus.

29. Boev V.A., Lezhnina A.A. Heavy metals in the snowpack of the Tyumen district, Tyumen region. Tyumen State University Herald. Natural Resource Use and Ecology, 2012, no. 7, pp. 41-48. In Rus.

30. Yazikov E.G., Talovskaya A.V., Zhornyak L.V. Otsenka ekologogeokhimicheskogo sostoyaniya territorii g. Tomska po dannym izucheniya pyleaerozoley i pochv: monografiva [Assessment of the ecological and geochemical state of the territory of Tomsk according to the study of dust aerosols and soils: monograph]. Tomsk, Tomsk Polytechnic University Publ., 2010. 264 p.

31. Litau V.V., Talovskaya A.V., Yazikov E.G., Lonchakova A.D., Tretyakova M.I. Dust pollution assessment on the territory of Omsk city using snow survey. Atmospheric and Oceanic Optics, 2015, vol. 28, no. 3, pp. 256-259. In Rus.

32. Ermolov Y.V., Smolentsev N.B. Background aerosol deposition in the south-eastern part of Western Siberia]. Atmospheric and Oceanic Optics, 2020, vol. 33, no. 1 (372), pp. 75-81. In Rus. DOI: 10.15372/AOO20200111

33. Onuchin A.A., Burenina T.A., Zubareva O.N., Trefilova O.V., Danilova I.V. Pollution of snow cover in the impact zone of enterprises in Norilsk industrial area. Contemporary Problems of Ecology, 2014, vol. 7, no. 6, pp. 714-722.

34. Talovskaya A.V., Filimonenko E.A., Yazikov E.G. Dynamics of the elemental composition of the snow cover in the north-eastern zone of influence of Tomsk-Seversk industrial agglomeration. Atmospheric and Oceanic Optics, 2014, vol. 27, no. 6, pp. 491-495. In Rus.

35. Talovskaya A.V. Geochemical characteristic of dust atmospheric precipitations on the Tomsk area. Atmospheric and Oceanic Optics, 2010, vol. 23, no. 6, pp. 519-524. In Rus.

36. Jarzyna K., Kozłowski R., Szwed M. Chemical properties of snow cover as an impact indicator for local air pollution sources. Infrastructure and Ecology of rural areas, 2017, vol. 4, no. 2, pp. 1591-1607. DOI: http://dx.medra.org/10.14597/infraeco.2017.4.2.120

37. Fakashchuk N.Yu., Soromotin A.V. Environmental assessment of the Tobolsk industrial zone territory. Tyumen State University Herald. Natural Resource Use and Ecology, 2017. vol. 3, no. 2, pp. 22-33. In Rus. DOI: 10.21684/2411-7927-2017-3-2-22-33

38. Li T., Wang Y., Li W.J., Chen J.M., Wang T., Wang W.X. Concentrations and solubility of trace elements in fine particles at a mountain site, southern China: regional sources and cloud processing. Atmospheric Chemistry and Physics, 2015, vol. 15, pp. 8987-9002. DOI: 10.5194/acp-15-89-87-2015

39. Dobrovolskiy V.V. Geografiya mikroelementov. Globalnoe rasseyanie [Geography of trace elements. Global scattering]. Moscow, Mysl Publ., 1983. 272 p.

40. Shevchenko V.P., Pokrovsky O.S, Vorobyev S.N., Krickov I.V., Manasypov R.M., Politova N.V., Kopysov S.G., Dara O.M., Auda Y., Shirokova L.S., Kolesnichenko L.G., Zemtsov V.A., Kirpotin S.N. Impact of snow deposition on major and trace element concentrations and elementary fluxes in surface waters of the Western Siberian Lowland across a 1700km latitudinal gradient. Hydrology and Earth System Sciences, 2017, vol. 21, pp. 5725-5746. Available at: https:// doi.org/10.5194/hess-21-5725-2017 (accessed 8 October 2020).

41. Guo L., Lyu Y., Yang Y. Concentrations and chemical forms of heavy metals in the bulk atmospheric deposition of Beijing, China. Environmental Science and Pollution Research, 2017, vol. 24, pp. 27356-27365. Available at: https://doi.org/10.1007/s11356017-0324-4 (accessed 8 October 2020).

42. Wu G., Wei Q., Sun C., Gao J., Pan L., Guo L. Determination of major and trace elements in snow in Tianjin, China: a threeheating-season survey and assessment. Air Quality, Atmosphere \& Health, 2016, vol. 9, pp. 687-696. Available at: https://doi.org/ 10.1007/s11869-015-0375-y (accessed 8 October 2020).

43. Kamani H., Hoseini M., Safari G.H., Jaafari J., Mahvi A.H. Study of trace elements in wet atmospheric precipitation in Tehran, Iran. Environmental Monitoring and Assessment, 2014, vol. 186, pp. 5059-5067. Available at: https://doi.org/10.1007/s10661-0143759-9 (accessed 8 October 2020).

44. Dong Z.W., Kang S.C., Qin X., Li X.F., Qin D.H., Ren J.W. New insights into trace elements deposition in the snow packs at remote 
alpine glaciers in the northern Tibetan Plateau, China. Science of the Total Environment, 2015, vol. 529, pp. 101-113. Available at: https://doi.org/10.1016/j.scitotenv.2015.05.065 (accessed 8 October 2020).

45. Ostromogilsky A.K., Anokhin Yu.A., Vetrov V.A., Petrukhin V.A., Poslovin A.L. Mikroelementy $v$ atmosfere fonovykh rayonov sushi i okeana. Kontrol zagryazneniya prirodnoy sredy. Obzornaya informatsiya. Vyp. 2 [Microelements in the atmosphere of background regions of land and ocean. Control of environmental pollution. Overview information. Iss. 2]. Obninsk, VNIIGMI-MCD information center Publ., 1981. $42 \mathrm{p}$.

46. Steinnes E., Friedland A.J. Metal contamination of natural surface soils from long-range atmospheric transport: existing and missing knowledge. Environmental Reviews, 2006, vol. 14, no. 3, pp. 169-186. Available at: https://doi.org/10.1139/a06-002 (accessed 8 October 2020).

47. Nriagu J.O., Pacyna J.M. Quantitative assessment of worldwide contamination of air, water and soils with trace elements. Nature, 1988, vol. 333, pp. 134-139.
48. Nechaeva E.G. Landshaftno-geokhimicheskiy analiz dinamiki tayezhnykh geosistem [Landscape-geochemical analysis of the dynamics of taiga geosystems]. Irkutsk, Institute of Geography USSR Academy of Sciences Publ., 1985. $210 \mathrm{p}$

49. Ljung K., Selinus O., Otabbong E., Berglund M. Metal and arsenic distribution in soil particle sizes relevant to soil ingestion by children. Applied Geochemistry, 2006, vol. 21, pp. 1613-1624. Available at: https://doi.org/10.1016/j.apgeochem.2006.05.005 (accessed 8 October 2020).

50. Kaasik M., Rõõm R., Røyset O., Vadset M., Sõukand Ü., Tõugu K., Kaasik H. Elemental and base anions deposition in the snow cover of north-eastern Estonia. The impact of industrial emissions. Water Air, and Soil Pollution, 2000, vol. 121, pp. 324-366. Available at: https://doi.org/10.1023/A:1005239810199 (accessed 8 October 2020).

Received: 12 April 2021.

\section{Information about the authors}

Dmitry V. Moskovchenko, Dr. Sc., principal scientist, Tyumen scientific center SB RAS.

Roman Yu. Pozhitkov, junior scientist, Tyumen scientific center SB RAS.

Andrey V. Soromotin, Dr. Sc., professor, Tyumen State University. 